Original

\title{
Increase in Serum Cannabinoids in a Rat Model of Septic Shock Induced by the Cell Wall Components of Staphylococcus aureus
}

\author{
Akira Fujimori, Masahiko MuraKami, \\ Masahiro WASEDA and Mitsuo KusANo
}

\begin{abstract}
During endotoxic shock, two endogenous cannabinoids, anandamide (ANA) and 2-arachidonoyl glycerol (2-AG), can be generated by activated macrophages and platelets and are thought to play a crucial role in the induction of shock-related hypotension. In vitro, the cell wall components of both Gram-positive and Gram-negative bacteria, can activate macrophages and release ANA. The aim of this study was to investigate whether cell wall components from Gram-positive bacteria could stimulate the release of ANA in an experimental animal model. Male Wistar rats were anesthetized and received an intravenous injection of lipoteichoic acid (LTA) and peptidoglycan (PepG) from Staphylococcus aureus. Mean arterial blood pressure (MAP) was monitored and blood samples were taken at $30 \mathrm{~min}$ and $360 \mathrm{~min}$ to measure ANA levels and other biochemical markers of multiple organ dysfunction syndrome (MODS). The administration of LTA and PepG resulted in a significant increase in the serum concentration of ANA (360 min, $n=4-6 ; P$ $<0.05$ ) and a biphasic fall in MAP from $103 \pm 1 \mathrm{mmHg}$ (time 0 ) to $50 \pm 4$ mmHg ( 360 min, $n=5 ; P<0.05)$. Furthermore, LTA + PepG was able to induce MODS as evidenced by a decrease in arterial oxygen tension (lung), an increase in serum levels of glutamate-pyruvate- and glutamate-oxaloacetatetransaminases (liver), and an increase in creatinine and blood urea nitrogen (kidney). These results, together with those of previous studies, imply that ANA is an endogenous mediator of shock-induced hypotension, in response to both endotoxin and Gram-positive bacteria.
\end{abstract}

Key words : anandamide, lipoteichoic acid, peptidoglycan, septic shock, Grampositive shock

\section{Introduction}

Despite remarkable improvements in critical care, sepsis and septic shock are still major causes of morbidity and mortality in medical and surgical ICUs. Although traditionally recognized as a consequence of Gram-negative bacteremia, sepsis can also be caused by Grampositive bacteria, fungi, and probably viruses and parasites. The incidence of Gram-positive septic shock has increased in the last decade, now accounting for $1 / 3$ to $1 / 2$ of all cases of sepsis $^{1)}$.

General Department of Surgery, Showa University School of Medicine, 1-5-8 Hatanodai, Shinagawa-ku, Tokyo, 1428555, Japan. 
Recent research has revealed some of the mechanisms involved in the progression of endotoxic shock. CD 14 and toll-like receptor-4 (TLR-4) are involved in lipopolysaccharide (LPS) signaling ${ }^{2-4)}$. LPS signaling in monocytes/macrophages results in the release of the endogeneous cannabioids, anandamide (ANA) and 2-arachydonil glycerol (2-AG), from macrophages and platelets, respectively. These endogenous cannabinoids mediate effects on various cells through $\mathrm{CB} 1, \mathrm{CB} 2$ and the vanilloid receptor, resulting in diverse biological effects including hypotension ${ }^{5,6)}$. Furthermore, they activate NF $\kappa$ B and stimulate the release of inflammatory cytokines which can cause circulatory failure and MODS ${ }^{7,8}$.

Polymixin B immobilized fiber (PMX-F) was developed in Japan as a biomaterial for selectively detoxifying endotoxin. Direct hemoperfusion (DHP) therapy with PMX-F is used as an effective medical treatment of early endotoxic shock patients in Japan ${ }^{9,10)}$. However, Wang et al reported that the rapid improvement of endotoxic shock patients with DHP therapy with PMX-F is due to the absorption of not only LPS but also the endogenous cannabinoids ${ }^{11)}$. Further research produced a sensitive method for detecting ANA and 2-AG using polymyxin B-selective absorption and subsequent high-performance liquid chromatography analysis ${ }^{12)}$.

In contrast to endotoxic shock, we know relatively little about the mechanisms by which Gram-positive bacteria cause shock and MODS. Pathological features of Gram-positive shock can be mimicked in anaesthetized rats by co-administration of lipoteichoic acid (LTA) and peptidoglycan (PepG), cell wall components from Staphylococcus aureus ${ }^{13,14)}$. In vitro studies show that PepG, in addition to LPS, can activate macrophages via the toll-like receptors (TLR) and cause the release of ANA., ${ }^{3,7)}$. However, no in vivo studies have been performed to investigate the role of endogenous cannabinoids in Gram-positive bacteremia. Here, we use the rat model of De Kimpe et $l^{13)}$ to investigate whether ANA is an endogenous mediator of hypotension induced by sepsis with Gram-positive bacteria.

\section{Materials and Methods}

\section{Animals}

Male Wistar rats weighing 250-300 g were obtained from Saitama Experimental Animals Supply Co. (Saitama, Japan). Rats were housed in the animal care facility unit maintained under controlled conditions $\left(23^{\circ} \mathrm{C}\right.$, light/dark cycles alternating every $12 \mathrm{~h}$ ) and received standard rodent chow and water ad libitum. The animals were cared for according to the guidelines provided by the National Institute of Health Guide for the Care and Use of Laboratory Animals.

\section{Haemodynamic measurements}

The animals were anesthetized by intraperitoneal injection of urethane $(1.2 \mathrm{~g} / \mathrm{kg})$. Rectal temperature was maintained at $37^{\circ} \mathrm{C}$. The right carotid artery was cannulated and connected to a pressure transducer (DTX PLUS; Ohmeda, Singapore PTE, Yishun, Singapore) to measure mean arterial blood pressure (MAP) and heart rate (HR). These were recorded throughout the experiment and displayed on an LEG-1000 system (Nihon Kohden Inc., Tokyo, Japan). The jugular vein was also cannulated for administration of drugs.

\section{Experimental protocol}

Upon completion of the surgical procedures, cardiovascular parameters were allowed to 
stabilize for $30 \mathrm{~min}$. At time 0 , animals received control $(0.3 \mathrm{ml}$, i.v. saline) or LTA (from $S$. aureus, Lot $100 \mathrm{~K} 4056,5 \mathrm{mg} / \mathrm{kg}$ in $0.3 \mathrm{ml}$ saline, i.v) plus PepG (from $S$. aureus, Lot 4 $6242 / 131801,12 \mathrm{mg} / \mathrm{kg}$ in $0.3 \mathrm{ml}$ saline, i.v), given as a slow infusion over $1-5 \mathrm{~min}$ in order to prevent a rapid fall in MAP. Haemodynamic measurements were recorded until sacrifice. At $30 \mathrm{~min}$ and $360 \mathrm{~min}$ after injections, blood was obtained (separate animals for each time point) from the carotid artery to measure changes in the serum levels of various biochemical markers of MODS, arterial blood gases, and the plasma levels of ANA. Lastly, the animals were sacrificed. Blood was centrifuged (3,000 r.p.m. for 10 mins at $4{ }^{\circ} \mathrm{C}$ ) to separate plasma and immediately frozen and stored at $-70^{\circ} \mathrm{C}$ until analysis.

\section{Biochemical markers of organ injury/dysfunction}

All serum samples were analyzed by a clinical chemistry laboratory (SRL, Inc., Tokyo, Japan). The following biochemical markers were measured as predictors of MODS :

1. glutamate-pyruvate-transaminase (GPT), a specific marker for hepatic parenchymal injury;

2. glutamate-oxalacetate-transaminase (GOT), a non-specific marker for hepatic parenchymal injury ;

3. bilirubin, a specific marker for the development of liver failure or cholestasis ;

4. creatinine, an indicator of reduced glomerular filtration rate, and therefore, renal failure ;

5. blood urea nitrogen, like urea, an indicator of impaired excretory function of the kidney and/or increased catabolism ;

6. blood gas analysis was performed using a Chiron $348 \mathrm{pH} /$ Blood Gas Analyzer (Chiron Diagnostics, Medfield, MA, USA.), which directly measures $\mathrm{pH}$, partial arterial carbon dioxide pressure $\left(\mathrm{PaCO}_{2}\right)$ and partial arterial oxygen pressure $\left(\mathrm{PaO}_{2}\right)$ and calculates bicarbonate ion $\left(\mathrm{HCO}_{3}{ }^{-}\right)$concentration.

\section{Measurement of serum levels of anandamide}

The serum levels of ANA were analyzed by the Osaka laboratory of Wako Pure Chemical Industries Ltd., kindly introduced by Professor Maruyama (Department of Laboratory and Molecular Medicine, Kagoshima University School of Medicine, Kagoshima, Japan). Measurements were performed using polymyxin B-selective absorption and subsequent high-performance liquid chromatography analysis according to the method described by Wang et $a l^{12)}$.

\section{Reagents}

All compounds were obtained from Sigma Chemical Co. (St. Louis, MO, USA) except $S$. aureus PepG which was obtained from Fluka Biochemica (Steinheim, Switzerland). All stock solutions were prepared in non-pyrogenic saline $(0.9 \% \mathrm{NaCl}$; Otsuka Pharmaceutical Co., Ltd., Tokyo, Japan) and care was taken to prevent endotoxin contamination. The suspension containing PepG was sonicated for $1 \mathrm{~min}$ before use.

\section{Statistical analysis}

All data are presented as mean (SE. Statistical analysis was performed using either an unpaired Student's t-test or a Mann-Whitney $U$-test. $P$ values less than 0.05 were considered statistically significant. The statistical analysis was performed using the Stat View 5.0 software for Windows (SAS Institute Inc., Cary, NC, USA). 


\section{Results}

Circulatory failure induced by $L T A+P e p G$

Baseline values for MAP and HR ranged from 99 to $109 \mathrm{mmHg}$ and from 270 to 410 beat $/ \mathrm{min}(\mathrm{n}=10)$, respectively. Injection of LTA $(12 \mathrm{mg} / \mathrm{kg})$ and PepG $(5 \mathrm{mg} / \mathrm{kg})$ resulted in a biphasic fall in MAP from $103 \pm 1 \mathrm{mmHg}$ (time 0 ) to $83 \pm 2 \mathrm{mmHg}$ at $10 \mathrm{~min}$. Thereafter, MAP recovered to $107 \pm 2 \mathrm{mmHg}$ at $120 \mathrm{~min}$. There was a further progressive fall in MAP to $50 \pm 3 \mathrm{mmHg}$ at $360 \mathrm{~min}$. MAP at $10 \mathrm{~min}, 30 \mathrm{~min}, 60 \mathrm{~min}$ and $360 \mathrm{~min}$ after injection of LTA and PepG $(n=5)$ was significantly lower than that following injection of saline $(n=5)$ (Fig. $1 ; P<0.05$, Student's t-test). LTA + PepG models showed a transient tachycardia ranging from $360 \pm 30 \mathrm{beat} / \mathrm{min}$ (time 0 ) to $430 \pm 30$ at $90 \mathrm{~min}$. The HR after injection of LTA and PepG $(n=5)$ was significantly lower than that of saline $(n=5)$ only at the $180 \mathrm{~min}$ mark (Fig. $2 ; P<0.05$, Student's t-test).

\section{MODS induced by LTA + PepG}

No significant differences in MODS markers were observed at $30 \mathrm{~min}$ between experimental models and control models. At $360 \mathrm{~min}$, LTA + PepG models showed a significant increase in all MODS markers except bilirubin (Table $1 ; P<0.05$, Student's t-test). At 30 min, blood $\mathrm{pH}$ and base excess were significantly decreased after injection of LTA + PepG (Table $1 ; P<0.05$, Student's t-test), while blood gases were not significantly different from controls at $30 \mathrm{~min}$. At $360 \mathrm{~min}$, LTA + PepG models showed a significant decrease in $\mathrm{PaO} 2$, indicating respiratory failure (Table $1 ; P<0.01$, Student's t-test). Blood $\mathrm{pH}$ and $\mathrm{PaCO}_{2}$ were not significantly affected at $360 \mathrm{~min}$. The calculated $\mathrm{HCO}_{3}{ }^{-}$concentration and base excess decreased. These results indicate a metabolic acidosis elicited by administration of LTA + PepG.

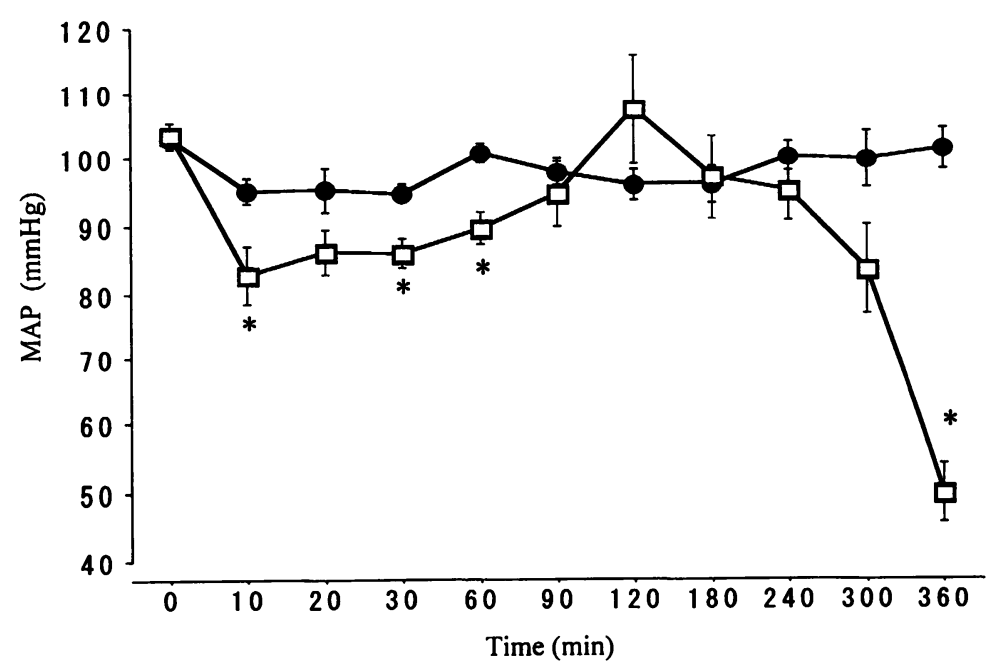

Fig. 1. Hypotension (mean arterial pressure) elicitid by lipoteichoic acid (LTA) and peptidoglycan (PepG). Rats were treated with LTA + PepG $(\square, n=5)$ or saline $(O, n=5)$. Results are expressed as mean \pm SE. ${ }^{*} P<0.05$ LTA + PepG vs. saline (Student's t-test) 


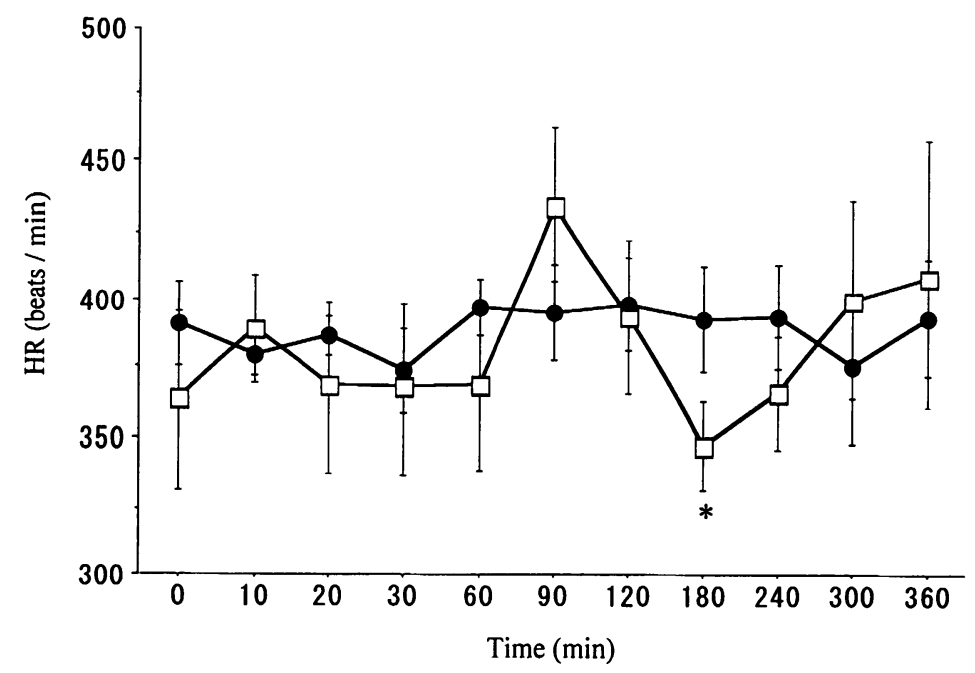

Fig. 2. Effects of lipoteichoic acid (LTA) and peptidoglycan (PepG) on HR (heart rate) Rats were treated with LTA + PepG $(\square, n=5)$ or saline $(O, n=5)$. Results are expressed as mean \pm SE. ${ }^{*} P<0.05$ LTA + PepG vs. saline (Student's t-test)

Table 1. Effects of LTA + PepG on (1) acid-base balance and blood gas (2) levels of biochemical markers of liver injury and renal failure

\begin{tabular}{lcccc}
\hline & \multicolumn{2}{c}{$30 \mathrm{~min}$} & \multicolumn{2}{c}{$360 \mathrm{~min}$} \\
\hline $\mathrm{pH}$ & Saline & LTA+PepG & Saline & LTA+PepG \\
PaCO2 (mmHg) & $7.43 \pm 0.01$ & $7.38 \pm 0.01^{* *}$ & $7.43 \pm 0.01$ & $7.41 \pm 0.03$ \\
PaO2 (mmHg) & $37.8 \pm 0.8$ & $39.6 \pm 1.0$ & $38.0 \pm 1.2$ & $33.2 \pm 2.1$ \\
HCO3-(mEq/1) & $79.7 \pm 1.7$ & $80.1 \pm 1.6$ & $74.2 \pm 1.1$ & $52.6 \pm 2.1^{* *}$ \\
Base excess (mmol/1) & $24.3 \pm 0.5$ & $22.9 \pm 0.6$ & $24.7 \pm 0.7$ & $20.3 \pm 1.3^{* *}$ \\
T-Bil (mg/dl) & $0.2 \pm 0.5$ & $2.0 \pm 0.6^{* *}$ & $0.7 \pm 0.6$ & $3.5 \pm 1.3^{* *}$ \\
GOT (IU/1) & $0.19 \pm 0.03$ & $0.26 \pm 0.04$ & $0.13 \pm 0.02$ & $0.27 \pm 0.08$ \\
GPT (IU/1) & $125.9 \pm 3.2$ & $132.7 \pm 8.5$ & $175.6 \pm 13.4$ & $261.9 \pm 27.3^{*}$ \\
BUN (mg/dl) & $40.4 \pm 2.3$ & $36.3 \pm 3.6$ & $42.3 \pm 1.9$ & $75.4 \pm 7.2^{* *}$ \\
Cre (mg/dl) & $14.4 \pm 1.8$ & $17.6 \pm 1.6$ & $123.2 \pm 0.8$ & $36.5 \pm 4.8^{* *}$ \\
\hline
\end{tabular}

The above parameters were measured $30 \mathrm{~min}$ or $360 \mathrm{~min}$ after injection of vehicle or lipoteichoic acid (LTA) + peptidoglycan (pepG). For abbreviations, see text. Data are expressed as mean \pm SE $(n=13)$

${ }^{*} P<0.05,{ }^{* *} P<0.01$ vs. saline-treated animals (Student's t-test)

Anandamide induced by $L T A+P e p G$

The baseline value for the serum level of ANA (time 0$)$ was $7.6 \pm 2.1 \mathrm{ng} / \mathrm{ml}(\mathrm{n}=5)$. ANA serum levels at 30 min after injection of LTA + PepG $(n=6)$ were significantly higher than that of saline $(\mathrm{n}=5)(40.8 \pm 8.2 \mathrm{ng} / \mathrm{ml}$ vs. $7.0 \pm 3.0 \mathrm{ng} / \mathrm{ml} ; P<0.01$, Mann-Whitney U-test). ANA levels were still increased at $360 \mathrm{~min}$ after injection of LTA+PepG $(\mathrm{n}=4)$ compared with saline injections $(\mathrm{n}=6)(21.2 \pm 4.1 \mathrm{ng} / \mathrm{ml}$ vs. $5.7 \pm 1.4 \mathrm{ng} / \mathrm{ml} ; P<0.01$, Mann-Whitney $U$-test) (Fig. 3). 

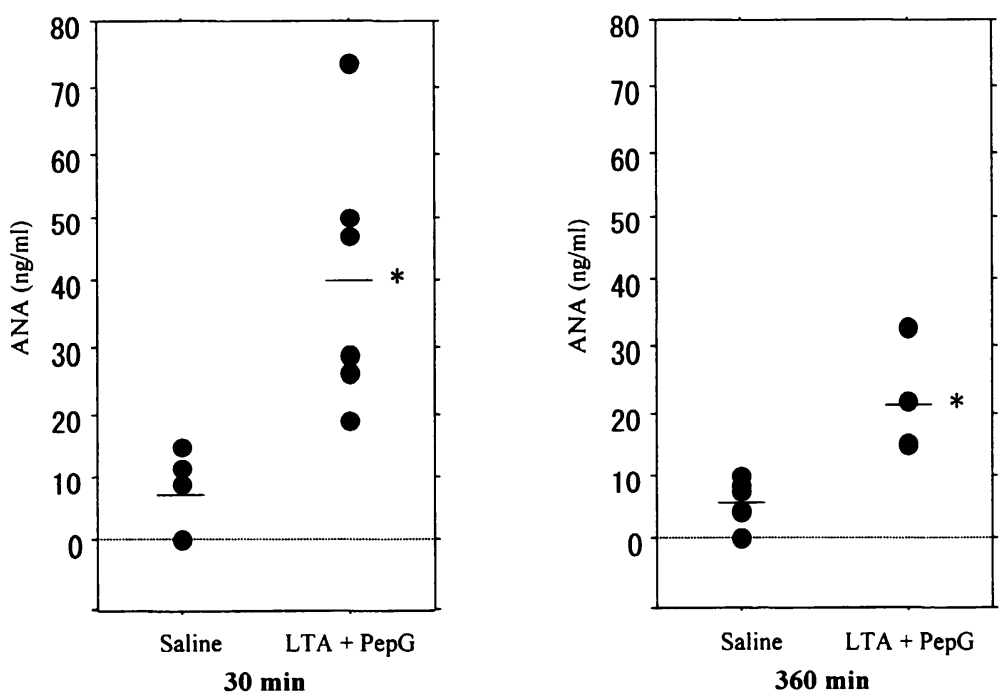

Fig. 3. Effects of lipoteichoic acid (LTA) and peptidoglycan (PepG) on the serum level of anandamide in rats. At $30 \mathrm{~min}$ or $360 \mathrm{~min}$ after injection of LTA + PepG or saline, anandamide levels in the serum are expressed as solid dots $(O, n=4-6)$. Each mean is expressed as a bar $(-) .{ }^{*} P<0.01 \mathrm{LTA}+$ PepG vs. saline (Mann-Whitney U-test)

\section{Discussion}

This study demonstrates that, in anesthetized rats, co-administration of two major cell wall components from S. aureus, LTA and PepG, can stimulate systemic release of ANA and induce septic shock. This is evidenced by the delayed circulatory failure (biphasic hypotension) and MODS, as measured by respiratory failure, liver failure and acute renal failure. There is also a metabolic acidosis. To induce significant hypotension, we needed to increase the dose of LTA and PepG compared with the model reported by De Kimpe et $a l^{13)}$ In their study LTA + PepG, in addition to LPS, resulted in systemic release of ANA in anesthetized rats. These results suggest that ANA is an endogenous mediator of hypotension induced not only by Gram-negative bacteria but also by Gram-positive bacteria. Further evidence also supports this idea. LTA and PepG are recognized by macrophages via TLR-4 and TLR-2, respectively, and they activate NF $\kappa B^{15,16)}$. In vitro exposure of macrophages to PepG also produces $\mathrm{ANA}^{7)}$. In septic patients carrying methicillin-resistant Staphylococcus aureus (MRSA) as well as Gram-negative bacteria, the serum levels of ANA are significantly increased. There is a significant decrease in serum levels of ANA following DHP therapy with PMX-F, which removes ANA from serum and improves the hemodynamic state in MRSA-induced septic patients ${ }^{8}$.

Our study showed a time-dependent progression of circulatory failure, respiratory dysfunction, liver injury, and metabolic acidosis, using a LTA + PepG rat model. However, ANA levels at $30 \mathrm{~min}$ were higher than that at $360 \mathrm{~min}$, demonstrating that the progression does not necessarily correlate with ANA levels. At $30 \mathrm{~min}$, the only significant differences seen in experimental animals were in MAP, blood $\mathrm{pH}$ and base excess, as well as a significant increase in ANA levels. ANA levels may even be more elevated before the 30 min mark. These results suggest that measurement of ANA levels in the early stages of 
sepsis may help to predict the likelihood of circulatory failure (hypotension) and MODS. Clinically, a level greater than $15 \mathrm{ng} / \mathrm{ml}$ may be significant.

Recent studies report that ANA is an early mediator of septic shock ${ }^{7)}$. ANA released from macrophages produces the inflammatory cytokines IL-1 and TNF- $\alpha$, and acts on cells, including macrophages, resulting in the extracellular translocation of High Mobility Group-1(HMG-1) from the nucleus. HGM-1 is thought to directly induce multiple organ failure $^{17)}$. Thus, HMG-1 acts downstream from ANA and functions as an endogenous mediator of septic shock in the later stages ${ }^{7)}$. Therefore, removal of or antagonism of ANA in the early stages of septic shock may protect against subsequent organ damage. Currently, DHP therapy with PMX-F is one of the most effective therapies for sepsis, regardless of whether it is secondary to infection with Gram-negative or Gram-positive bacteria. When sepsis is suspected, this therapy should be initiated immediately. In the future, treatment regimes may involve administration of an ANA receptor antagonist during the earliest stages.

In conclusion, we showed that the cell wall components from Gram-positive bacteria cause systemic release of ANA and induce septic shock in an experimental animal model. This result suggests that ANA is an endogenous mediator of shock-induced hypotension from sepsis due to both Gram-negative and Gram-positive bacteria.

\section{Acknowledgements}

We thank Prof. Ikuro Maruyama and Wako Pure Chemical Industries, Ltd. for the measurement of anandamide levels.

\section{References}

1) Bone RC: Gram-positive organisms and sepsis. Arch Intern Med 154 : 26-34 (1994)

2) Wright SD, Ramos RA, Tobias PS, Ulevitch RJ and Mathison JC: CD14, a receptor for complexes of lipopolysaccharide (LPS) and LPS binding protein. Science 249 : 1431-1433 (1990)

3) Lien E, Means TK, Heine H, Yoshimura A, Kusumoto S, Fukase K, Fenton MJ, Oikawa M, Qureshi N, Monks B, Finberg RW, Ingalls RR and Golenbock DT : Toll-like receptor 4 imparts ligand-specific recognition of bacterial lipopolysaccharide. J Clin Invest 105 : 497-504 (2000)

4) Thomas JA : Toll genes and responsiveness to bacterial endotoxins. N Engl J Med 342 : 664-665 (2000)

5) Varga K, Wagner JA, Bridgen DT and Kunos G : Platelet- and macrophage-derived endogenous cannabinoids are involved in endotoxin-induced hypotension. FASEB J 12 : 1035-1044 (1998)

6) Zygmunt PM, Petersson J, Andersson DA, Chuang H, Sorgard M, Di Marzo V, Julius D and Hogestatt ED : Vanilloid receptors on sensory nerves mediate the vasodilator action of anandamide. Nature 400:452-457 (1999)

7) Maruyama I : Paradigm sift in endotoxin shock : roles of endogenous cannabinoides and HMG-1. ICU \& CCU 24 : 865-874 (2000) (in Japanese)

8) Imaizumi H, Sumita S, Masuda Y, Maruyama I, Asai Y and Namiki A : Absorption of endogeneous cannabinoid, anandamide using DHP wit h polymyxin B immobilized fiber improves hemodynamic state in septic patients. ICU \& CCU $25: 555-563$ (2001) (in Japanese)

9) Hanasawa K, Tani $T$ and Kodama $M$ : New approach to endotoxin and septic shock by means of polymyxin B-immobilized fiber. Surg Gynecol Obstet $168: 323-331$ (1989)

10) Kodama M, Tani $T$ and Hanasawa $K$ : Treatment of sepsis by plasma endotoxin removal. Hemoperfusion using a polymyxin B-immobilized column. J Endotoxin Res 4 : 293-300 (1997)

11) Wang Y, Liu Y, Sarker KP, Nakashima M, Serizawa T, Kishida A, Akashi M, Nakata M, Kitajima I and Maruyama I : Polymyxin B binds to anandamide and inhibits its cytotoxic effect. FEBS Lett 470 : 151-155 (2000)

12) Wang $Y$, Liu $Y$, Ito $Y$, Hashiguchi T, Kitajima I, Yamakuchi M, Shimizu H, Matsuo S, Imaizumi H and Maruyama I : Simultaneous measurement of anandamide and 2-arachidonoylglycerol by polymyxin b-selective adsorption and subsequent high-performance liquid chromatography analysis. Increase in endogenous cannabinoids in the sera of patients with endotoxic shock. Anal Biochem 294: 73-82 (2000) 
13) De Kimpe SJ, Kengatharan M, Thiemermann C and Vane JR: The cell wall components peptidoglycan and lipoteichoic acid from Staphylococcus aureus act in synergy to cause shock and multiple organ failure. Proc Natl Acad Sci USA 92 : 10359-10363 (1995)

14) Kengatharan KM, De Kimpe SJ and Thiemermann C: Role of nitric oxide in the circulatory failure and organ injury in a rodent model of gram-positive shock. Br $J$ Pharmacol 119 : 1411-1421 (1996)

15) Liu Y, Wang Y, Yamakuchi M, Isowaki S, Nagata E, Kanmura Y, Kitajima I and Maruyama I : Upregulation of toll-like receptor 2 gene expression in macrophage response to peptidoglycan and high concentration of lipopolysaccharide is involved in NF-kappa b activation. Infect Immun $69: 2788-2796$ (2001)

16) Takeuchi O, Hoshino K, Kawai T, Sanjo H, Takada H, Ogawa T, Takeda K and Akira S : Differential roles of TLR2 and TLR4 in recognition of gram-negative and gram-positive bacterial cell components. Immunity 11 : 443-451 (1999)

17) Wang H, Bloom O, Zhang M, Vishnubhakat JM, Ombrellino M, Che J, Frazier A, Yang H, Ivanova S, Borovikova L, Manogue KR, Faist E, Abraham E, Andersson J, Andersson U, Molina PE, Abumrad NN, Sama $A$ and Tracey KJ : HMG-1 as a late mediator of endotoxin lethality in mice. Science 285:248-251 (1999)

[Received February 5, 2002 : Accepted February 14, 2002] 